\title{
Short communication \\ Sperm DNA damage in relation to lipid peroxidation following freezing-thawing of boar semen
}

\author{
L. Fraser ${ }^{1 \#}$, J. Strzeżek ${ }^{1}$, K. Wasilewska ${ }^{1} \&$ C.S. Pareek ${ }^{2}$ \\ ${ }^{1}$ Departmentof Animal Biochemistry and Biotechnology, Faculty of Animal Bioengineering \\ University of Warmia and Mazury in Olsztyn, 10-719 Olsztyn, Poland \\ ${ }^{2}$ Functional Genomics in Biological and Biomedical Research, Centre for Modern Interdisciplinary Technologies, \\ Nicolaus Copernicus University, Torun, Poland
}

(Received 21 January 2017; Accepted 28 February2017; First published online 8 March 2017)

Copyright resides with the authors in terms of the Creative Commons Attribution 4.0 South African License.
See: http://creativecommons.org/licenses/by/4.0/za
Condition of use: The user may copy, distribute, transmit and adapt the work, but must recognize the authors and the South African
Journal of Animal Science.

\begin{abstract}
This study investigated the relationships between lipid peroxidation (LPO) and sperm DNA damage following freezing-thawing of boar semen in different extenders. The comet assay was used to measure the extent of sperm DNA damage in a cryoprotectant-free extender or in cryoprotectant-based extenders after single and repeated freezing and thawing. As well as an analysis of sperm motion characteristics, mitochondrial function, membrane integrity, and lipid peroxidation (LPO) were assessed simultaneously with the measurements of sperm DNA damage. Consistent positive significant correlations were found between sperm DNA damage and LPO after freezing-thawing. Comet assay measurements showed that cryo-induced sperm DNA damage was more marked in the cryoprotectant-free extender, irrespective of freezing cycle. The frequency of sperm cells with damaged DNA increased with repeated freezing and thawing in the cryoprotectant-based extenders. Except for sperm DNA damage, there were no consistent associations between post-thaw sperm LPO and sperm quality characteristics. It could be suggested that the increased LPO of membrane phospholipids is associated with higher susceptibility of boar spermatozoa to cryoinduced DNA damage.
\end{abstract}

Keywords: Comet assay measurements, cryopreservation, extenders, spermatozoa

${ }^{\#}$ Corresponding author: fraser@uwm.edu.pl

Evidence has shown that reduced fertilizing ability of frozen-thawed spermatozoa is because of compromised viability, DNA integrity, and increased peroxidative damage (Thompson et al., 2009; Fraser et al., 2010; Hamilton et al., 2016; Fraser et al., 2016). Intact sperm DNA integrity is essential for fertilization and embryo development (Evenson, 2016). Accumulating evidence has shown that sperm DNA damage is a useful marker for post-thaw semen quality (Fraser et al., 2010; Gosálvez et al., 2011; Gürler et al., 2016). Cryo-induced oxidative stress, associated with excess reactive oxygen species (ROS), has a negative effect on sperm nuclear DNA integrity (Peris et al., 2007; Thompson et al., 2009; Gürler et al., 2016). Moreover, lipid peroxidation (LPO) cascade is initiated by oxidative challenge on the membrane phospholipids of spermatozoa, which significantly compromises their function (Neild et al., 2005; Whitaker et al., 2012; Hamilton et al., 2016). Studies on the relationships between DNA damage and LPO of frozen-thawed boar spermatozoa are limited. This study therefore investigated the relationships between sperm DNA damage and LPO following freezing-thawing of boar semen in a cryoprotectant-free extender or in cryoprotectantbased extenders supplemented with whole hen egg yolk (HEY), ostrich egg yolk (OEY) and lipoprotein fractions isolated from OEY (LPFo). Repeated freezing and thawing of semen samples was performed to assess its effect on post-thaw sperm DNA integrity.

Sperm-rich fractions (SRFs) were collected from five Polish Large White boars (average age 18 months), using the gloved-hand technique (King \& Macpherson, 1973). The animals were stationed at the Cryopreservation Laboratory at the University of Warmia and Mazury in Olsztyn, Poland, and experiments were carried out in accordance with the guidelines set out by the local ethics committee. The SRFs were collected weekly from the five boars for a three-week period in autumn-winter from October through March, giving a total number of 15 SRFs, three from each of the five boars. The SRFs were processed with a cryoprotectant-free extender (Kortowo 3, K3), without the supplementation of cryoprotective additives, and 
cryoprotectant-based extender containing HEY, OEY, or LPFo (Fraser et al., 2010; Strzeżek et al., 2014; Fraser et al., 2016). Briefly, semen samples were held in cooling extenders containing $11 \%$ lactose with $20 \%$ HEY (lactose-HEY extender), 20\% OEY (lactose-OEY extender), or 11\% lactose with 5\% lyophilized LPFo (lactose-LPFo extender) for 2 hours at $5{ }^{\circ} \mathrm{C}$, prior to the addition of glycerol and Orvus Es Paste (lactoseHEY-G, lactose-OEY-G or lactose-LPFo-G extenders). All cooled semen samples were packaged into 10-ml aluminum tubes, frozen in a programmable computer freezer (Ice Cube 1810, SY-LAB) and stored in liquid nitrogen for at least one week prior to post-thaw analysis. At thawing, a portion of the semen samples from each extender (K3, lactose-HEY-G, lactose-OEY-G and lactose-LPFO-G extenders) was removed, reloaded into the aluminum tubes and frozen again (repeated freezing and thawing). The frozen semen was stored in liquid nitrogen prior to the assessment of sperm DNA damage.

Sperm quality characteristics were assessed in raw fresh and frozen-thawed semen. The LPO was measured as the production of malondialdehyde (nMol MDA by $1 \times 10^{8}$ spermatozoa), using the thiobarbituric acid (TBA) assay (Fraser et al., 2016). Sperm motion parameters, assessed by the computerassisted sperm analysis (CASA) system (SM-CMA Stromberg-Mika Medical Equipment), included total motility (TMOT) (\%), linear motility (LMOT) (\%), velocity straight line (VSL) $(\mu \mathrm{m} / \mathrm{s})$, velocity average pathway $(\mathrm{VAP})(\mu \mathrm{m} / \mathrm{s})$, velocity curvilinear $(\mathrm{VCL})(\mu \mathrm{m} / \mathrm{s})$, amplitude of lateral head displacement $(\mathrm{ALH})(\mu \mathrm{m})$, and beat cross frequency (BCF) (Hz). The percentages of spermatozoa with functional mitochondria and normal apical ridge (NAR) acrosome integrity were assessed according to an earlier study (Fraser et al., 2010). Sperm plasma membrane integrity (PMI) (\%) was monitored with the live/dead sperm viability kit, and molecular probes (Garner \& Johnson, 1995). The comet assay was used to measure sperm DNA fragmentation (Fraser et al., 2010; Fraser et al., 2016). Sperm cells were classified as spermatozoa with non-fragmented DNA and with fragmented DNA (\%).Comet software analysis (Komet Image Analysis System, version 5.0, Kinetic Imaging Ltd., Liverpool, UK) was used to analyse the comet tail measures, such as the tail length $(\mu \mathrm{m})$ and olive tail moment (OTM) (expressed as an arbitrary units) (Fraser et al., 2016). The variables of both comet tail length and OTM were log-transformed to achieve normally distributed data. The data were subjected to ANOVA repeated measures with boar as a random factor. Two fixed factors, extenders and treatment (single and repeated freezing and thawing), were used to assess post-thaw sperm DNA damage (Neuman-Keuls post hoc test; $P<0.05$ ). A $3 \times 2$ factorial design (boar $\times$ extender) was used to assess the quality characteristics of frozen-thawed spermatozoa. Pearson rank correlations were used to examine the relationships between post-thaw LPO and the comet assay parameters and sperm quality characteristics. All data were analysed with the general linear model (GLM) procedure from Statistica software package, version 10 (StatSoft Inc., Tulsa, OK, USA).

The sperm quality characteristics in fresh raw boar semen are shown in Table 1. Furthermore, sperm DNA fragmentation in raw fresh semen averaged $2.8 \pm 1.2 \%$, whereas the values for the comet tail length and OTM were $7.8 \pm 1.1 \mu \mathrm{m}$ and $2.2 \pm 0.4$ (arbitrary units), respectively. Besides boar variability, extender was a significant source of variations $(P<0.001)$ in most of the analysed sperm quality characteristics following freezing-thawing. Spermatozoa frozen in the lactose-OEY-G extender were more susceptible to cryo-induced damage compared with those frozen in the lactose-HEY-G extender (Table 1). Significantly greater $(P<0.05)$ LPO in frozen-thawed spermatozoa of the lactose-OEY-G extender was concurrent with higher $(P<0.05)$ TMOT, LMOT, VSL and VAP. A similar trend was observed with the percentages of frozenthawed spermatozoa with functional mitochondria and intact plasma membrane. Interestingly, only frozenthawed spermatozoa from the lactose-OEY-G extender showed negative correlations between LPO and mitochondrial function $(r=-0.28, P<0.05)$, and PMI $(r=-0.44, P<0.001)$.

Besides boar variability, extender and freezing cycle had a marked effect $(P<0.001)$ in the analysed comet assay measures. Repeated freezing and thawing induced significant changes $(P<0.05)$ in the sperm DNA integrity, particularly in the cryoprotectant-free extender (Figure 1A). Among the cryoprotectant-based extenders, post-thaw sperm DNA fragmentation was significantly lower $(P<0.05)$ in the lactose-HEY-G extender, regardless of the freezing cycle (Figure 1A). Comet tail length (Figure 1B) and OTM (Figure 1C) showed that repeated freezing and thawing increased $(P<0.05)$ the extent of sperm DNA damage, particularly in the cryoprotectant-free and lactose-OEY-G extenders.

The findings of the study are consistent with previous observations, which indicated that the freezingthawing process increases the susceptibility of boar spermatozoa to peroxidative damage, resulting in impaired motility, and reduced plasma membrane and DNA integrity (Fraser et al., 2010; Whitaker et al., 2012; Fraser et al., 2016). Similar findings have been reported for post-thaw spermatozoa of stallions (Neild et al., 2005), ram (Peris et al., 2007; Hamilton et al., 2016), humans (Thompson et al., 2009), and bulls (Gürler et al., 2016). 
Table 1 Sperm quality characteristics in raw fresh and frozen-thawed boar semen

\begin{tabular}{|c|c|c|c|c|}
\hline \multirow{2}{*}{ Sperm parameters (mean \pm SEM) } & \multirow{2}{*}{$\begin{array}{l}\text { Fresh semen } \\
\quad(n=15)\end{array}$} & \multicolumn{3}{|c|}{ Frozen-thawed semen $(n=15)$} \\
\hline & & Lactose-HEY-G & Lactose-OEY-G & Lactose-LPFo-G \\
\hline LPO (nM MDA $/ 10^{8}$ spermatozoa/h) & $21.2 \pm 2.3$ & $28.1^{\mathrm{a}} \pm 0.9$ & $34.7^{b} \pm 1.1$ & $30.1^{\mathrm{ab}} \pm 2.3$ \\
\hline Total motility (\%) (TMOT) & $88.5 \pm 1.5$ & $38.9^{\mathrm{a}} \pm 1.1$ & $28.3^{\mathrm{b}} \pm 2.2$ & $32.2^{\mathrm{ab}} \pm 1.7$ \\
\hline Velocity straight line (VSL) $(\mu \mathrm{m} / \mathrm{s})$, & $70.3 \pm 2.2$ & $60.3^{a} \pm 2.1$ & $52.5^{b} \pm 1.7$ & $55.9^{\mathrm{ab}} \pm 2.9$ \\
\hline Velocity average-pathway (VAP) $(\mu \mathrm{m} / \mathrm{s})$ & $82.4 \pm 1.6$ & $52.9^{\mathrm{a}} \pm 2.4$ & $40.9^{b} \pm 1.4$ & $48.8^{\mathrm{ab}} \pm 1.3$ \\
\hline Velocity curvilinear (VCL) $(\mu \mathrm{m} / \mathrm{s})$ & $155.3 \pm 4.1$ & $130.5^{\mathrm{a}} \pm 2.8$ & $127.7^{\mathrm{a}} \pm 3.1$ & $131.4^{\mathrm{a}} \pm 3.2$ \\
\hline $\mathrm{ALH}(\mu \mathrm{m})$ & $7.3 \pm 0.5$ & $7.1^{a} \pm 0.8$ & $7.5^{\mathrm{a}} \pm 0.7$ & $7.2^{\mathrm{a}} \pm 0.5$ \\
\hline Beat cross frequency $(\mathrm{Hz})$ & $31.6 \pm 1.1$ & $29.3^{\mathrm{a}} \pm 1.0$ & $28.4^{\mathrm{a}} \pm 2.4$ & $31.5^{\mathrm{a}} \pm 1.8$ \\
\hline Mitochondrial function (\%) & $90.6 \pm 1.0$ & $51.9^{\mathrm{a}} \pm 1.3$ & $40.4^{b} \pm 1.2$ & $49.6^{\mathrm{ab}} \pm 1.5$ \\
\hline Plasma membrane integrity (\%) (PMI) & $91.3 \pm 0.7$ & $53.7^{\mathrm{a}} \pm 1.4$ & $45.9^{b} \pm 1.3$ & $50.1^{\mathrm{ab}} \pm 2.0$ \\
\hline NAR acrosome integrity (\%) & $94.5 \pm 0.8$ & $52.8^{\mathrm{a}} \pm 2.7$ & $48.5^{\mathrm{a}} \pm 3.6$ & $49.0^{\mathrm{a}} \pm 1.4$ \\
\hline
\end{tabular}

${ }^{a, b}$ Row means with different superscripts differ significantly at $P<0.05$ (Neuman-Keuls post hoc test); lactose-HEY-G: lactose-whole hen egg yolk-glycerol extender; lactose-OEY-G: lactose-whole ostrich egg yolk-glycerol extender; lactoseLPFo-G: lactose-ostrich egg yolk lipoprotein fraction-glycerol extender; LPO: lipid peroxidation; MDA: malondialdehyde; ALH: amplitude of lateral head displacement; NAR: normal apical ridge
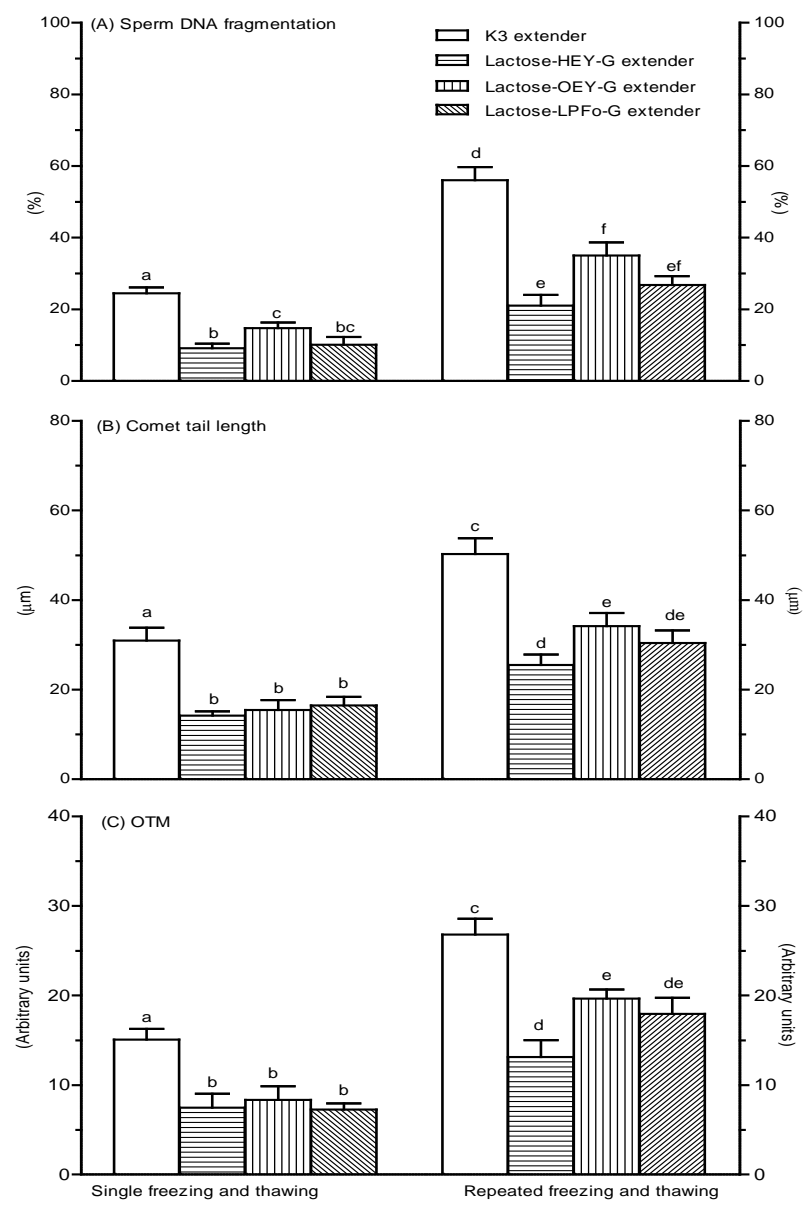

Figure 1 Post-thaw DNA damage of boar spermatozoa, represented by (A) DNA fragmentation, (B) tail length DNA comet and (C) olive tail moment (OTM). Values represent the means of ( \pm S.E.M) of 15 ejaculates $\mathrm{a}, \mathrm{b}, \mathrm{c}, \mathrm{d}, \mathrm{e}, \mathrm{f}$ Values with different letters differ significantly at $P<0.05$ 
The results of this study showed that the freezing-thawing cycle caused marked variations in post-thaw DNA damage among the cryopreservation extenders. However, the degree of cryo-induced sperm DNA damage, analysed by comet tail length or OTM, did not significantly vary among the cryopreservation-based extenders. In a recent study, the authors showed that comet tail length and OTM are consistent in the detection of cryo-induced DNA damage, and are more reliable parameters than the percent tail DNA to reflect the extent of the sperm DNA damage (Fraser et al., 2016). In the current study, comet tail measures showed that repeated freezing and thawing of boar semen exacerbated sperm DNA damage, regardless of the cryopreservation extender. Similar findings have been reported for frozen-thawed human spermatozoa (Thomson et al., 2010; Liu et al., 2016). Moreover, repeated freezing and thawing may maximize the use of spermatozoa, particularly for assisted reproductive techniques (Thomson et al., 2010), even though it has been reported that the repeated cryo-cycle might compromise sperm DNA integrity and viability (Liu et al., 2016).

Consistent significant correlations were found between the comet assay parameters and LPO in all the extenders (Table 2). However, strong $(P<0.001)$ positive correlations were found between the comet assay parameters and LPO for the cryoprotectant-free extender following freezing-thawing. In addition, DNA fragmentation, comet tail length of OTM were highly $(P<0.001)$ positively correlated with LPO, particularly for the lactose-OEY-G extender. The consistent significant associations between sperm DNA damage and LPO reinforce the observation that frozen-thawed spermatozoa are highly susceptible to oxidative stress, which has a detrimental effect on the DNA-protamine complex. Even though the mechanisms of oxidative stressinduced LPO and sperm DNA damage are not fully understood, it seems that increased cryo-induced oxidative stress generated via LPO may activate an apoptotic-like phenomenon, leading to sperm DNA damage. Similar assumptions have been suggested by other authors (Neild et al. 2005; Thompson et al., 2009; Hamilton et al. 2016). However, it is difficult to explain the lack of consistent correlations between LPO and the sperm quality characteristics in most of the cryoprotectant-based extenders. LPO and membrane damage are relatively independent processes that occur during the freezing-thawing of mammalian spermatozoa (Neild et al., 2005). Moreover, LPO, which occurs in the sperm mid-piece depends mainly on

Table 2 Correlations between DNA damage and lipid peroxidation (LPO) of frozen-thawed boar spermatozoa

A. $\mathrm{K} 3$ extender

\begin{tabular}{|c|c|c|c|}
\hline Comet assay parameters & 1 & 2 & 3 \\
\hline 1. DNA fragmentation & & & \\
\hline 2. Comet tail length & $0.42^{\star *}$ & & \\
\hline 3. Olive tail moment (OTM) & $0.41^{\star *}$ & $0.44^{\star \star}$ & \\
\hline 4. Lipid peroxidation (LPO) & $0.66^{\star \star \star}$ & $0.56^{\star \star \star}$ & $0.58^{\star \star \star}$ \\
\hline \multicolumn{4}{|l|}{ B. Lactose-HEY extender } \\
\hline \multicolumn{4}{|l|}{ 1. $\quad$ DNA fragmentation } \\
\hline 2. Comet tail length & $0.41^{* *}$ & & \\
\hline 3. Olive tail moment (OTM) & $0.40^{*}$ & $0.42^{\star \star}$ & \\
\hline 4. Lipid peroxidation (LPO) & $0.54^{\star \star *}$ & $0.45^{\star \star}$ & $0.37^{*}$ \\
\hline \multicolumn{4}{|l|}{ C. Lactose-OEY extender } \\
\hline 1. DNA fragmentation & & & \\
\hline 2. Comet tail length & $0.28^{*}$ & & \\
\hline 3. Olive tail moment (OTM) & $0.32^{*}$ & $0.41^{\star \star}$ & \\
\hline 4. Lipid peroxidation (LPO) & $0.49^{\star *}$ & $0.51^{\star \star *}$ & $0.55^{\star \star \star}$ \\
\hline \multicolumn{4}{|l|}{ D. Lactose-LPFo extender } \\
\hline 1. DNA fragmentation & & & \\
\hline 2. Comet tail length & $0.40^{*}$ & & \\
\hline 3. Olive tail moment (OTM) & $0.29 *$ & $0.36^{*}$ & \\
\hline 4. Lipid peroxidation (LPO) & $0.54^{\star \star \star}$ & $0.42^{\star \star}$ & $0.43^{\star \star}$ \\
\hline
\end{tabular}

${ }^{*} P<0.05 ;{ }^{* \star} P<0.01 ;{ }^{* \star *} P<0.001$ 
the measurement of malondialdehyde (MDA) production, and its levels do not always provide enough information about the membrane status in spermatozoa (Neild et al., 2005; Hamilton et al., 2016). The findings of this study suggest that further research, probably with a more sensitive LPO membrane probe, is required to assess precisely the membrane lipid status in spermatozoa following freezing-thawing.

Among the cryopreservation-based extenders, spermatozoa frozen-thawed in the lactose-OEY-G extender were more susceptible to DNA damage and LPO, as observed in reduced post-thaw sperm quality characteristics. Even though there were no significant correlations, these data suggest that the disturbance in sperm membrane structures was concomitant with increased LPO following freezing-thawing. However, there is still controversy about whether membrane damage is caused by increased LPO or is a consequence of higher LPO (Neild et al., 2005). It has been confirmed that cryo-induced oxidative stress enhances LPO followed by high levels of sperm membrane damage (Neild et al., 2005; Hamilton et al., 2016). In the current study, such observation was more marked in frozen-thawed spermatozoa of the lactose-OEY-G extender. The authors suggest that differences in the biochemical components of the HEY, OEY, or LPFo could account for the marked variations in sperm cryo-survival. Another possible explanation for this phenomenon could be the high proportions of dead frozen-thawed spermatozoa in the lactose-OEY-G extender, which might be an additional source of production of reactive oxygen species (ROS) resulting in compromised sperm viability and DNA integrity (Roca et al., 2016). Similar assumptions have been suggested for the wide variations in cryo-induced sperm DNA damage for boar semen frozen in various avian egg yolk-based extenders (Strzeżek et al., 2014; Fraser et al., 2016). Moreover, the impact of freezing-thawing was not limited to disturbing the genomic integrity of spermatozoa, but caused dramatic changes in the expression levels of several epigenetic-related genes (Zeng et al., 2014; Hamilton et al., 2016). These factors are associated with poor survival of embryo post fertilization, with consequent increased incidence of embryo mortality (Gosálvez et al., 2011; Evenson, 2016).

In conclusion, this study confirms that increased sperm DNA damage is associated with higher LPO in frozen-thawed boar spermatozoa. Given the increasing knowledge of the authors about the functional implications of the associations of DNA damage with LPO of membrane phospholipids of frozen-thawed spermatozoa, an on-going study has been focused to chemically modify the extender composition to confer maximum protection to spermatozoa against oxidative stress during semen cryopreservation.

\section{Acknowledgements}

This study was supported by the State Committee for Scientific Research (Project: PBZ-KBN-084/PO6/2002) and by a project from the National Science Centre, Poland (2015/19/B/NZ9/01333).

\section{Authors' Contributions}

LF conducted the semen quality research and was responsible for drafting and submitting the manuscript. JS provided critical review of the manuscript. KW was responsible for providing additional literature to the manuscript. CSP assisted in the revision of the manuscript.

\section{Conflict of Interest Declaration}

None of the authors has any conflict of interest to declare.

\section{References}

Evenson, D.P., 2016. The sperm chromatin structure assay (SCSA $®)$ and other sperm DNA fragmentation tests for evaluation of sperm nuclear DNA integrity as related to fertility. Anim. Reprod. Sci.169, 56-75.

Fraser, L., Parda, A., Filipowicz, K. \& Strzeżek, J., 2010. Comparison of post-thaw DNA integrity of boar spermatozoa assessed with the neutral Comet assay and Sperm-Sus Halomax test kit. Reprod. Domest. Anim. 45,e155-e160.

Fraser, L., Zasiadczyk, Ł. \& Pareek, C.S., 2016. Effects of boar variability on comet-detected sperm-DNA damage following cryopreservation. Anim. Prod. Sci. (in press). DOI: 10.1071/AN16274.

Garner, D.L. \& Johnson, L.A., 1995. Viability assessment of mammalian sperm using SYBR-14 and propidium iodide. Biol. Reprod. 53, 276-284.

Gosálvez, J., López-Fernández, C., Fernández, J.L., Gouraud, A. \& Holt, W.V., 2011. Relationships between the dynamics of latrogenic DNA damage and genomic design in mammalian spermatozoa from eleven species. Mol. Reprod. Develop. 78, 951-961.

Gürler, H., Malama, E., Heppelmann, M.O., Calisici, O., Leiding, C., Kastelic, J. P. \& Bollwein, H., 2016. Effects of cryopreservation on sperm viability, synthesis of reactive oxygen species and DNA damage of bovine sperm. Theriogenology 86, 562-571.

Hamilton, T.R., de Castro, L.S., Delgado, J.C., de Assis, P.M., Siqueira, A.F.P., Mendes, C.M., Goissis, M.D., MuiñoBlanco, T., Cebrián-Pérez, J.Á., Nichi, M., Visintin, J.A. \& Assumpção, M.E.O.D., 2016. Induced lipid peroxidation in ram sperm: semen profile, DNA fragmentation and antioxidant status. Reproduction 151(4), 379-390.

King, G.J. \& Macpherson, J.W.,1973. A comparison of two methods for boar semen collection. J. Anim. Sci. 36, $563-565$.

Liu, L., Gao, J., Zhou, N., Mo, M., Wang, X., Zhang, X., Yang, H., Chen, Q., Ao, L., Liu, J., Cui, Z. \& Cao, J., 2016.The effect of two cryopreservation methods on human sperm DNA damage. Cryobiology 72 (3), 210-215. 
Neild, D.M., Brouwers, J.F., Colenbrander, B., Agüero, A. \& Gadella, B.M., 2005. Lipid peroxide formation in relation to membrane stability of fresh and frozen thawed stallion spermatozoa. Mol. Reprod. Dev. 72(2), 230-238.

Peris, S.I., Bilodeau, J.F., Dufour, M. \& Bailey, J.L., 2007. Impact of cryopreservation and reactive oxygen species on DNA integrity, lipid peroxidation, and functional parameters in ram sperm. Mol. Reprod. Dev. 74,878-892.

Roca, J., Parrilla, I., Gil, M.A., Cuello, C., Martínez, E.A. \& Rodríguez-Martínez, H., 2016. Non-viable sperm in the ejaculate: Lethal escorts for contemporary viable sperm. Anim. Reprod. Sci. 169, 24-31.

Strzeżek, J., Fraser, L., Lecewicz, M., Strzeżek, R. \& Dziekońska, A., 2014. Preparation for the preservation of animal semen, particularly of boar. Patent Number: PL217869-B1. UWM in Olsztyn.

Thomson, L.K., Fleming S.D., Barone, K., Zieschang, J.A. \& Clark, A.M., 2010. The effect of repeated freezing and thawing on human sperm DNA fragmentation. Fertil. Steril. 93 (4),1147-1156.

Thomson, L.K., Fleming, S.D., Aitken, R.J., De Iuliis, G.N., Zieschang, J.A. \& Clark, A.M., 2009. Cryopreservationinduced human sperm DNA damage is predominantly mediated by oxidative stress rather than apoptosis. Hum. Reprod. 24, 2061-2070.

Whitaker, B.D., Casey, S.J. \& Taupier, R., 2012. N-acetyl-L-cysteine supplementation improves boar spermatozoa characteristics and subsequent fertilization and embryonic development. Reprod. Domest. Anim. 47, 263-268.

Zeng, C., Peng, W., Ding, L., He, L., Zhang, Y., Fang, D. \& Tang, K., 2014. A preliminary study on epigenetic changes during boar spermatozoa cryopreservation. Cryobiology 69,119-127. 